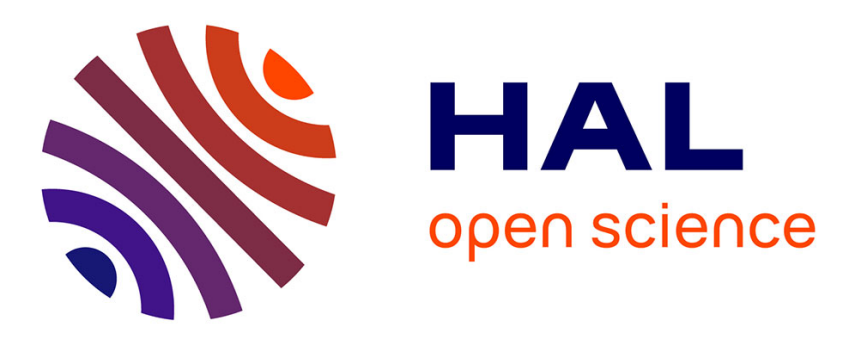

\title{
Conventional approaches to the modelling of a dysfunctional process in the context of maintenance activity
}

Pascal Vrignat, Manuel Avila, Florent Duculty, Frédéric Kratz

\section{To cite this version:}

Pascal Vrignat, Manuel Avila, Florent Duculty, Frédéric Kratz. Conventional approaches to the modelling of a dysfunctional process in the context of maintenance activity. Electrotechnical Conference, The 14th IEEE Mediterranean, IEEE MELECON, May 2008, AJACCIO, France. pp.41-47. hal00594888

\section{HAL Id: hal-00594888 \\ https://hal.science/hal-00594888}

Submitted on 23 Jun 2011

HAL is a multi-disciplinary open access archive for the deposit and dissemination of scientific research documents, whether they are published or not. The documents may come from teaching and research institutions in France or abroad, or from public or private research centers.
L'archive ouverte pluridisciplinaire HAL, est destinée au dépôt et à la diffusion de documents scientifiques de niveau recherche, publiés ou non, émanant des établissements d'enseignement et de recherche français ou étrangers, des laboratoires publics ou privés. 


\title{
Conventional approaches to the modelling of a dysfunctional process in the context of maintenance activity
}

\author{
P. Vrignat, M. Avila, F. Duculty, F. Kratz
}

\begin{abstract}
: this article presents a set of conventional approaches to the modelling of dysfunctioning of a process in the context of maintenance activities. It recalls advantages and disadvantages in their use. The normative framework of maintenance, the priorities of the long-term maintenance and the content of the maintenance function will also be presented. This paper presents a state of the research of usual maintenance methods. We give hints about the use of these methods for new products for emaintenance.
\end{abstract}

Index Terms: modelling, maintenance, process, classical approach.

\section{INTRODUCTION}

$\mathrm{H}$ uman and industrial activities often headline the news with their trails of incidents or serious accidents. Indeed, zero defect (zero risk) is not possible, unfortunately. In an attempt to minimize these risks, methods, techniques and scientific tools were developed in the 20th century to assess potential risks, predict the occurrence of failures and attempt to minimize the consequences of catastrophic situations. All these scientific and methodological developments relate to the discipline of Dependability. It consists in knowing, assessing, predicting and controlling technological system failures and human errors. Good quality maintenance will be reached if both the human and technological factors are associated. The Fig. 1[1] summarizes our issue.

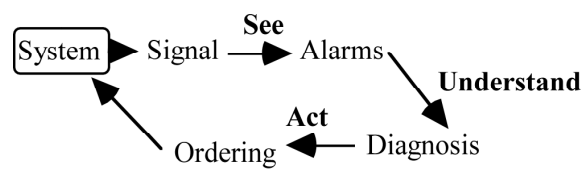

Fig. 1. The three stages of diagnosis process

The analysing methods as a helping tool in the decision making process emerged in the 60's and were initiated by Barlow, Proschan, Jorgenson, MC Call, Radner and Hunter. Their different results are summarized in J. McCall [2]. In [3] Robin P. Nicolai gives an overview of the literature on multicomponent maintenance optimisation. For Dekker [4], the

P. Vrignat, M. Avila, F. Duculty, F. Kratz work in PRISME InstituteMCDS Team - Orleans University - IUT Chateauroux - France. (e-mail: pascal.vrignat@univ-orleans.fr). model for optimising maintenance is a mathematical one in which the costs and benefits of maintenance are quantified and a balance is achieved between them while taking into account

the constraints of production. In general, the optimisation models of maintenance cover four aspects:

- the technical description of the system, its functions and its importance,

- modelling the process of system failure and the possible consequences,

- the system information and required actions for its management,

- the determination of the objective function with optimisation techniques necessary to find the possible optimum.

These models use the techniques of linear and nonlinear optimisation, dynamic programming, Markov decisions, failure trees, Bayesian statistics decision, expert systems ... The expected results for these models are different. There is no generic model for optimising maintenance. The prospects for the optimisation models of maintenance are interesting for two main reasons:

- the technological need and the economic necessity,

- the increase in invested capital.

In general, the models will have to assess the economic consequences of the decisions made. Of all the methods of diagnosis and detection, two approaches emerge regularly: the first approach is known as deterministic or classical, the second is a probabilistic approach.

The work presented in this article is divided into three parts. As a first step, we will focus on key definition in maintenance and the evolution of this discipline. In the second chapter, we will develop a state of the research on a wide range of methods used for decision support as part of an approach known as "classical". Finally, we will present some bibliographic references of the different existing methods, and give hints for their usage for new products of automation and e-maintenance services.

\section{DEFINITION OF MAINTENANCE}

IEC 60300-3-14 standards [32] define maintenance as all actions which allow the maintaining or restoring of a property in a specified state or the provision of a specific service. Retour and al. [5] present the maintenance function as a series 
of activities grouped into two subsets: technical activities and management operations. The maintenance process is described in greater detail in [6]. In this context of complexity of production, the twin challenge "Implementation of principles of sustainable development / Improving flexibility and responsiveness of the company towards the development of the product" requires that each sub production makes its own contribution to the achievement of the overall performance. In this way, the process of $\mathrm{CBC}^{1}$ implements a set of activities and logistics (supply, acquisition and management of spare parts, maintenance operations, tools, documentation, training...) with the final aim of ensuring the operational stage (either production or service) of the given system [7].

\section{MAINTENANCE FUNCTION}

In the definition of maintenance, we find two keywords: to maintain and to restore. The first one refers to preventative action. The second one refers to corrective action. We can summarize the different policies which govern the relevant maintenance Fig. 2. B. Castanier [8] proposes a synthesis of these different strategies for maintenance. Sometimes, the choice of a policy is imposed, as is the case with nuclear power in France.

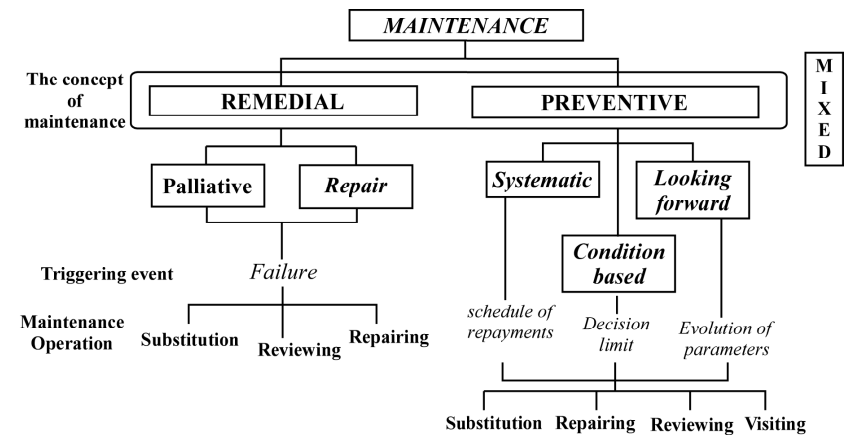

Fig. 2. Example of maintenance policy

\section{EVOLUTION OF THE DISCIPLINE}

\section{A. The safety of operation}

The dependability is called the science of "failures", but also risk analysis (environment), science of danger, RAMS ${ }^{2}$. This is characterized by both static and dynamic structural studies of systems, but also forecasts operational and experimental ones (tests, accidents), taking into account the probabilistic aspects and consequences induced by technical and human failures. This discipline is involved not only in systems that have already been built, but also at the design level for the implementation of the systems. Dependability, which was developed mainly during the 20th century as an unavoidable area for hazardous industries, is now, increasingly used, for all industries, because of its correlation with the notion of quality, ergonomic issues (human relations) and the impact on the environment. Before the Second World War, dependability was more an art than an empirical and accurate science.

\section{B. The concept of reliability of a system}

A system can be defined as a set of interrelated components, which are designed to perform a given function, in given conditions and during a given lapse of time. The reliability of a system is expressed by the probability that the device performs a required function under conditions of use and for a given lapse of time [10]. This is expressed as a magnitude from 0 to 1. We refer to it, as the following, $\mathrm{R}(\mathrm{t})$ where $\mathrm{t}$ refers to the duration of the mission.

$$
\mathrm{R}(\mathrm{t})=\mathrm{P}\{\text { Lifetime System }>\mathrm{t}\}
$$

The fact that the failure of a system can occur at any time leads us to consider this magnitude as a random variable to which we can associate a probability density function $\mathrm{f}(\mathrm{t})$. It is important to remember that $\mathrm{f}(\mathrm{t})$. $\mathrm{dt}$ is the probability that the lifespan of a system is between $t$ and $t+d t$, or the likelihood that it fails between $t$ and $t+d t$ (Fig. 3 ).

$$
\mathrm{f}(\mathrm{t}) \cdot \mathrm{dt}=\mathrm{P}\{\mathrm{t}<\text { Lifetime System }<\mathrm{t}+\mathrm{dt}\}
$$

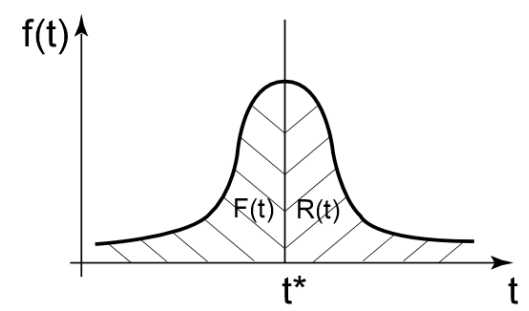

Fig. 3. The density function of lifetime

$F(t)$ is the distribution function associated to lifetimes. $F(t)$ may be interpreted as the probability that the system still works at $t$ [14]. The failure of equipment can be characterized by the breakdown rate $(\lambda)$. It is defined as the conditional probability that the equipment broke down between the time $t$ and $t+\Delta t$ knowing that it has survived until the point in time $t$. It can also be defined by the equation 3 . It also represents the suddenness of the blackout [11].

$$
\lambda(t)=\frac{N(t)-N(t+\Delta t)}{N(t) \Delta t}
$$

With :

- $N(t)$ : number of components that survived until instant $\mathrm{t}$,

- $\quad N(t+\Delta t)$ : number of components that survived until instant $\mathrm{t}+\Delta \mathrm{t}$.

During the lifetime of an entity, we see that its failure rate evolves along its life. This is known as the "bathtub" curve as shown in Fig. 4 [14].

\footnotetext{
${ }^{1}$ Continued Business Conditions from the military sphere

${ }^{2}$ Reliability, Availability, Maintainability and Safety
} 


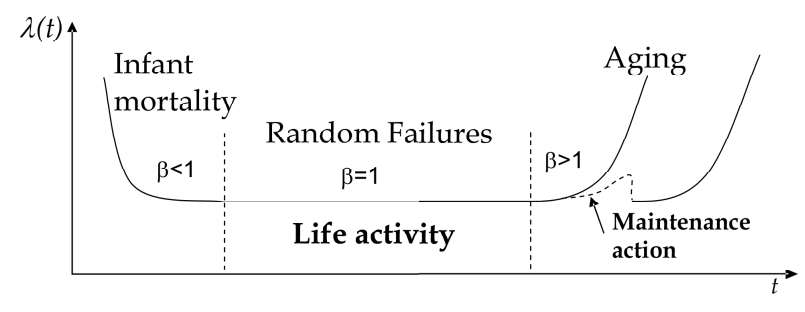

Fig. 4. The bathtub curve

The Weibull distribution [12], [13] is the most commonly used system to model the function of reliability $R(t)$ of a component or a machine. It makes it's possible to model the evolution of the failure rate $\lambda(t)$ (4), during the three periods of its life: youth, exploitation and old age (Fig. 4):

$$
\lambda(t)=\frac{\beta}{\eta}\left(\frac{t-\gamma}{\eta}\right)^{\beta-1}
$$

(with $\beta$ shape parameter, $\eta$ scaling parameter, $\gamma$ offset parameter).

\section{The concept of availability of a system}

The standard [32] defines availability as " the ability of an entity to perform a required function under given conditions at a given time or over a given lapse of time, assuming the external means providing that necessary maintenance is assured. " The probability of $\mathrm{A}(\mathrm{t})$ at instant $\mathrm{t}$ is also called availability and is shown by the Equation 5:

$$
A(t)=P(\text { project operating at } t)
$$

The opposite of availability is called unavailability and is defined as (Equation 6):

$$
\bar{A}=1-\mathrm{A}(\mathrm{t})
$$

Caution: Availability A(t) is an instant value. The entity may have failed and been repaired before time $t$, unlike the reliability $\mathrm{R}(\mathrm{t})$ which is a quantity measured over a period (interval $[0, \mathrm{t}]$ ). The confusion between availability and reliability is due to the fact that these two notions are equivalent when the system is not repairable. The physical interpretation is shown in Fig. 5 [14]: availability as a function of time $t$ when entities are represented or available as at time $\mathrm{t}=0$.

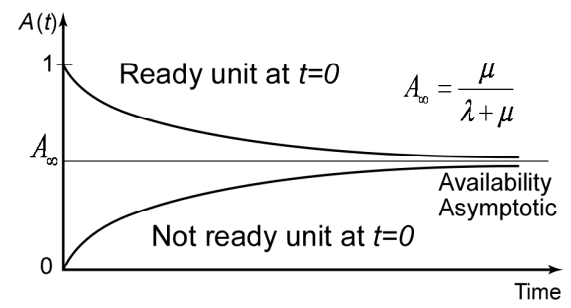

Fig. 5. Availability as a function of time $t$
In industry, given an effective maintenance policy, and after a given lapse of time, entities reached the asymptotic availability limit.

As with reliability, many types of availability can be used such as instant, or mean availability.

The average values associated to the availability of the most common are illustrated in Fig. 6:

$$
\mathrm{MTBF}=\mathrm{MUT}+\mathrm{MDT}
$$

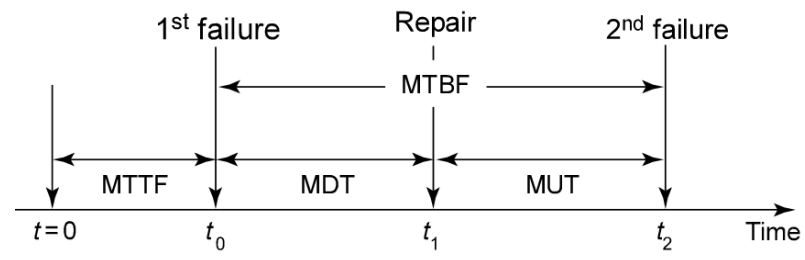

Fig. 6. Representation $\mathrm{MTBF}^{3}, \mathrm{MDT}^{4}, \mathrm{MUT}^{5} \& \mathrm{MTTF}^{6}$

The asymptotic availability can be deducted from the MUT and the MTBF by the relationship:

$$
A_{\infty}=\frac{M U T}{M T B F}
$$

\section{Classical APPROACH FOR THE MODELING OF A SYSTEM DYSFUNCTION}

This is mainly used when the amount of feedback data is sufficiently important. This approach of dysfunctions of systems consists in identifying the conditions that can lead to failures and predicts their impact on the reliability, maintainability, availability and security of systems being developed or already operational [14]. The required information for the analysis consist of:

- the description of the real system,

- the characteristics of the system components and the interactions between them,

- the relationship between the system and its environment,

- the need to take into account human error in the operating stage.

\section{A. Description of analytical methods forecasting}

The analytical methods forecasts are divided into two main families that differ in the techniques of reasoning:

- Inductive methods (bottom to top) from the causes of failures to the consequences that we want to avoid,

- Deductive methods (top to bottom) are in contrast to the bottom-up methods: we start from the problem down to the causes that may lead to this event [14].

The implementation of these methods needs a hierarchical or functional description of the system. These methods, favoured

\footnotetext{
${ }^{3}$ Mean Time Between Failure

${ }^{4}$ Mean Down Time

${ }^{5}$ Mean Up Time

${ }^{6}$ Mean Time To Failure
} 
by some industrial sectors, will now be presented in this paragraph:

- Failure Mode, Effects and Criticality Analysis (FMECA) NASA, 1960's,

- HAZard and OPerability study (HAZOP), 1970's,

- Reliability Block Diagram Method (RBDM),

- $\quad$ Truth Table Method (TTM), 1815's,

- $\quad$ Fault Tree Method, 1960's,

- Event Tree Method (ETM), 1970's,

- Diagram Method (DM), 1970's,

- Hidden Markov Model, 1950's,

- Petri Nets, 1960's,

- $\quad \ldots$

B. State of the Art: modeling methods in the context of a deterministic approach

1) Cause Tree Method or Failure Tree Method (CTM / FTM), combinatorial techniques.

It is a top to bottom method (from general to particular). This method was developed in 1961-1962 for the Bell Telephone Company by A. Watson (Fault Tree Analysis, FTA). It consists in taking into account a system failure and then generating a list from top to bottom of all the various failures triggered by the initial problem. That problem being the cause, will be referred to as the "top event". Middle or bottom failures are represented in Fig. 7. The Fig. 7 represents the most common symbols used to build a fault tree. There is no unique model for the reaction of the system's failures [15]. Analyzing failures can generate all the cuts (such as a diagram of reliability of which it is a "dual") and to derive the "minimum" cuts as shown, for example, in Fig. 7 [15].

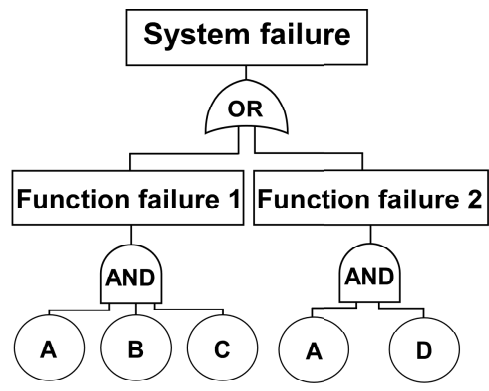

\begin{tabular}{|c|l|l|}
\hline \multicolumn{1}{|c|}{$\begin{array}{c}\text { Minimum } \\
\text { cut }:\end{array}$} & \multicolumn{1}{c|}{$\mathrm{AD}$} & \multicolumn{1}{c|}{$\mathrm{ABC}$} \\
\hline$Q_{\text {cut }}(t)=\prod_{i=1}^{n} Q_{i}$ & $Q_{a} Q_{d}$ & $Q_{a} Q_{b} Q_{c}$ \\
\hline$w_{\text {cut }}(t)=\sum_{i=1}^{n} w_{i} \prod_{\substack{j \neq i \\
j=1}}^{n} Q_{i}$ & $w_{a} Q_{d}+w_{d} Q_{a}$ & $\begin{array}{l}w_{a} Q_{b} Q_{c}+w_{b} Q_{a} Q_{c} \\
+w_{c} Q_{a} Q_{b}\end{array}$ \\
\hline
\end{tabular}

Fig. 7. Sample of minimal cuts

M. Bouissou and A. Floria [16] show that this approach can be used to build, operate and formalize models with a knowledge base such as BDMP (Boolean logic Driven Markov Process). Other applications have shown that this description is also used as part of a BDMP [17].
2) Truth Table Method and the Decision-Making Table (TTM,DMT)

Based on Boolean algebra, the truth table method identifies all states (operation or failure) of the system from its binary behaviour.

3) Consequence Tree Method or Event Tree Method (CTM, ETM)

The use of this method dates back to the 70's in the United States where is was used for risk assessment in nuclear power plants. This method is derived from the method of decision trees (decision analysis) [18], [19], [20]. A sequence of events is triggered by an initiator event and a combination of failures and operation of safety systems. It is described as unacceptable or acceptable according to the consequences it triggers [14]. Fig. 8 represents a tree of events.

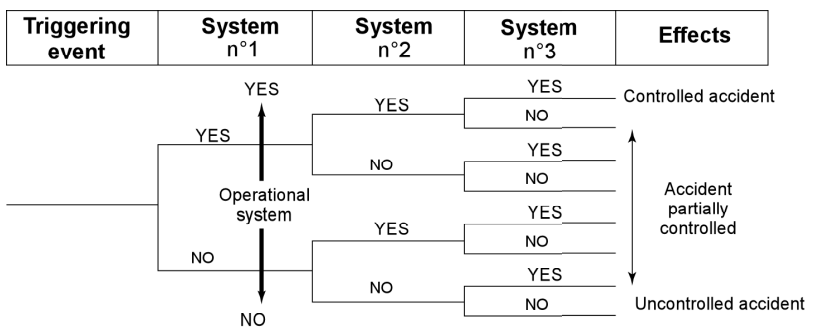

Fig. 8. A tree event example

4) Cause Consequence Diagram Method (CCDM)

Developed in the 70's by the national laboratory Ris0 in Denmark, the Cause Consequence Diagram (CCD) is a combination of CTM and ETM [9]. It implements both the inductive logic of the Consequence Tree (CT) and the deductive logic of the Cause Tree for Failures (CTF). So, a Cause Consequence Diagram consists in one or more "summits" such as a (CTF) leading to undesirable consequences, feared or unacceptable, and part "consequences" which corresponds to the events summits. As for CTF, specific symbols are used in the construction of $\mathrm{CCD}$, the cause preserving the CTF conventions. The symbols specific to CCD are shown in the TABLE 1 [9]. The construction of a CCD follows the rules of CTF and cumulative $\mathrm{CT}$, and is accomplished by selecting an initiator event, and then seeking the causes (CTF) and consequences (CT) of this event. Secondly, the establishment of cuts, then minimum cuts, yields quantitative results.

TABLE 1

EXAMPLES OF SYMBOLS USED IN CAUSES CONSEQUENCES DIAGRAMS

\begin{tabular}{|c|c|c|}
\hline SYMBOL & SYMBOL NAME & REMARKS \\
\hline$f^{\text {Input }}$ & \multirow{4}{*}{ Door « YES / NO » } & \multirow{4}{*}{$\begin{array}{l}\text { The output event is "YES" } \\
\text { If the condition is fulfilled, "NO" } \\
\text { A causal tree explaining the } \\
\text { causes of failure of the condition } \\
\text { can be developed on the left. }\end{array}$} \\
\hline Condition & & \\
\hline YES & & \\
\hline+ & & \\
\hline Input & & \\
\hline & $\begin{array}{l}\text { "Overdue " } \\
\text { Operator }\end{array}$ & $\begin{array}{l}\text { The event output occurs in a time } \\
\text { after the event } D \text { input. }\end{array}$ \\
\hline$\downarrow$ Output & & \\
\hline
\end{tabular}




\section{5) State Space Method (SSM)}

This approach was first developed for the study of "Markov type" stochastic processes. It combines the system components, depending on their condition: operating or failing. The parameters $\lambda$ (failure rate) and $\mu$ (rates of compensation) allow us to specify different stages of transitions as represented in Fig. 9.

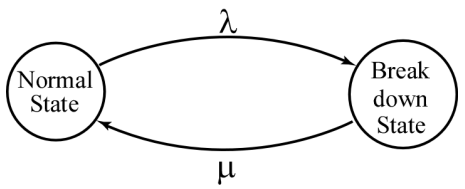

Fig. 9 Markov model

a) Markov processes, homogeneous Markov systems

The Markov processes enable us to study the evolution of systems over time, considering that the present state is independent of the past state of the system. We talk about Markov chains if the process is discrete. If transitions are characterized by an independent lapse of time (constant), the process is labelled, "homogeneous Markov" [14]. S. BlochMercier [21] presents the final maintenance moments as moments of Markov renewal for which it is possible to calculate the asymptotic unavailability by following the principles outlined in this paragraph. C. Meier-Himer [22] proposes an approach to estimate the parameters of lifetime laws of catenary parts using a statistical method based on the Markov chains and Markov processes jumps. B. Castanier [23] proposes a condition-based maintenance policy for a repairable system subject to a continuous state gradual deterioration monitored by sequential non-periodic inspections. This approach makes it's possible to study the reliability of these parts.

b) Semi-Markov Process

A semi-Markov process shows that the probability of transition from one state to another depends only on the elapsed time since the arrival in this state. Such a process leads to a coupled system of equations which can be solved analytically [14]. M.A. Boyd [24] explains widely this method in this application note. J. Lonchampt [25] proposes a model of risk quantification for a preventative maintenance program for a repairable component.

c) Stochastic Petri Nets

A stochastic Petri network is a Petri network with which a random variable with non-negative real values is associated. These variables then model a random duration sensibilisation. A transition period $t$ of $\tau$ constant sensibilisation, corresponds to a random variable law, the measurement of the Dirac point $\tau$. When $\tau=0$, the transition will be called "immediate", its likelihood will be higher than other transitions [26]. Other laws of probability (Exponential, Weibull, Uniform...) characterize the random delay of transitions [27]. In general, random transitions are obtained with the help of timed Petri nets [28] and [29]. In Petri nets timers, a period of crossing is associated with each transition, and corresponds with the waiting time between the time of authorization and the crossing of the transition. In Stochastic Petri Nets (SPN), this waiting time is a random variable. In the simplest case, it is assumed that the random variable associated to a transition $t$ is distributed according to an exponential law with the parameter:

$$
\alpha \mathrm{t}=1 /(\text { average waiting time })[30]
$$

The Fig. 10 presents an example of a stochastic network, which models $n$ equipments which may fail following an exponential law parameter $\lambda$ and may be repaired following an exponential law parameter $\mu$.

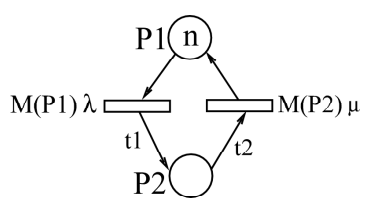

Fig. 10 Stochastic Petri nets

A random variable law parameter $\mathrm{T}$ exponentially multiplied by the number of chips in P1 (resp. parameter $\mu \mathrm{xM}(\mathrm{P} 2)$ ) is associated to the transition $\mathrm{t} 1$ (resp. $\mathrm{t} 2$ ). It is necessary in some cases to assign a discrete probability distribution on a subset of transitions. The probability of successful startup is equal to $\frac{\omega 1}{\omega 1+\omega 2}$ [26]. A. Aghasaryan [30] gives a special credit to the expansion of SPN; the most widely used are the Generalized Stochastic Petri Nets Networks (GSPN), [29] [31]. GSPN are obtained by defining two classes of transitions:

- immediate transitions,

- delayed transitions.

They have the same meaning as in the SPN standard. The immediate transitions, however, have a crossing time equal to zero, and therefore have a higher likelihood compared to delayed transitions.

\section{BENEFITS, DRAWBACKS, USE OF RUNNING DIFFERENT METHODS}

\section{A. Cause Tree Method or Failure Tree Method (CTM / FTM), combinatorial techniques}

These methods makes it possible to provide criteria to determine the priorities for the prevention of potential accidents. Easy to read, there are fastidious when it applies to an full system. It is used in aerospace, nuclear or chemical industries to analyze the causes of accidents.

\section{B. Truth Table Method and the Decision-Making Table (TTM,DMT)}

There are simple methods, but only give binary solutions. Its require the study of all combinations of operation or failure of a component with "yes / no" or "true / false".

\section{Consequence Tree Method or Event Tree Method (CTM, ETM)}

These methods consider the sequence of events that could lead to an accident or potential incident, and means of security arising therefrom. Complex, there are used in nuclear to 
estimate the probabilities of accident occurrences.

\section{Cause Consequence Diagram Method (CCDM)}

It is the simultaneous analysis of the causes and consequences of an event. It is used in the prevention of occupational safety, but could not be applied to complex problems.

\section{E. State Space Method (SSM)}

This method is based on the probabilistic analysis of Markov models, and therefore rests on the interpretation of the frequency of results. It is used in many fields, but it can not handle synchronization operations.

\section{F. Stochastic Petri Nets}

These are powerful tools for modelling, analysing and evaluating systems. Its provide useful graphics, but its require expensive tools in the field of simulation. There are many applications in telecommunications and mobile robotics.

\section{THOSE METHODS FOR GUIDANCE OF E-MAINTENANCE ACTIVITIES}

The advantages, disadvantages and uses are widely described in [15] and [33]. But a most important question arises: What can be expected from these methods ? Can they now be integrated into the new products for e-maintenance ? The manufacturer OMRON [34] offered integrated preventative emaintenance in a series of product DRT2. These "smart" slaves can be regulated by upstream causes-consequences diagrams. Can the new generations of Programmable Logic Controller (PLC) already add or will they shortly be able to add to their processing capabilities, features that only a "super computer" is able to deal with today by using methods, such as, stochastic methods (Markov,...) or artificial intelligence algorithms (neural networks,...) ? The answer is yes ! Indeed, today NeuroSystems and Siemens with FuzzyControl $++[38]$ offer two software environments using those methods in perfect compatibility with PLC, an application of supervision, or even an operator. Within the European project PROTEUS [37] model of cooperative systems can be implemented using Petri nets [35] or $\mathrm{HMM}^{7}$ [36]. The use of new technologies of communication in products of automation provides new kind of services. But considering this discussion on maintenance an other question arises: with a constant volume of maintenance activities, can we have a better availability of the manufacturing process by improving the organization of maintenance activities ? Our ongoing work consist of trying to answer this question.

\section{REFERENCES}

[1] M. Basseville, and M.O. Cordier, "Surveillance et diagnostic de systèmes dynamiques : approches complémentaires du Traitement de Signal et de l'Intelligence Artificielle. ", Rapport de Recherche INRIA 2861, 1996.

[2] J. McCall, « Maintenance Policies for Stochastically Failing Equipment: A Survey, » Management Science, Vol. 11, pp. 493-524, 1965.

\footnotetext{
${ }^{7}$ Hidden Markov Models
}

[3] R. P. Nicolai, R. Dekker, « Optimal Maintenance of Multi-Component Systems : a Review » Econometric Institue Report 2006-29, August 2006.

[4] R. Dekker, " Applications of maintenance optimization models : a review and analysis ", pages 229-240, volume 51, Issues 3, Reliability Engineering and Safety Journal, March 1996.

[5] D. Retour, M. Bouche et V. Plauchu, "Où va la maintenance industrielle, Problèmes Économiques », No. 2.159, pp. 7-13, 24 Janvier 1990.

[6] J.C. Francastel, « La fonction maintenance. De l'expression à la satisfaction du besoin. », AFNOR Editions. Paris, 1999.

[7] J.L. Combeau, « Situation et tendances de l'évolution de la maintenance chez les donneurs d'ordres industriels », Etude réalisée en 2002 par l'ADEPA sous l'égide du Ministère de l'Economie, des Finances et de l'Industrie, avec le concours de l'AFNOR, l'AFIM et du CNMI. 2002.

[8] B. Castanier, " Modélisation stochastique et optimisation de la maintenance conditionnelle des systèmes à dégradation graduelle », Thèse de doctorat, Université de Technologie de Troyes, 2001.

[9] G. Zwingelstein, « Diagnostic des défaillances, théorie et pratique pour les systèmes industriels. », Ed. HERMES, 1995.

[10] AFNOR, Guides de l'utilisateur : Contrats de maintenance, 2ème édition, 1988.

[11] F. Monchy, « La fonction maintenance : Formation à la gestion de la maintenance industrielle ", Collection technologies de l'université à l'industrie, MASSON, 1991.

[12] S. Martorell, A. Sanchez and V. Serradell, « Age-dependent reliability model considering effects of maintenance and working conditions ", Reliability Engineering and System Safety, 64(1), pp. 19-31, 1999.

[13] P. Vlok, J. Coetzee, D. Banjevic, A. Jardine and V. Makis, " Optimal component replacement decisions using vibration monitoring and the proportional-hazards model », Journal of the Operational Research Society, 53, 193-202, 2003.

[14] G. Zwingelstein, «Sûreté de fonctionnement des systèmes industriels complexes », Revue ISSN 1632-3831, 1999.

[15] B. Guaglio, Fiabilité : Comment répondre à la question «le système, marchera-t-il ?», CERN, juin 2005.

[16] M. Bouissou, A. Floria, " Manuel d'utilisation de la base de connaissances BDMP pour KB3 », HT-52/03/039/A, EDF-R\&D, 2003.

[17] M. Bouissou, "Recherche de séquences avec FIGSEQ : Exemples d'application avec les BDMP, EDF R\&D et CNRS UMR 8050 », 2005.

[18] M. Bouissou, " Deux méthodes originales pour calculer les performances d'un système possédant des états de fonctionnement dégradé ", 12ème colloque de fiabilité et maintenabilité, $\operatorname{lm} 12$, Montpellier, mars 2000.

[19] C. Bonnet, "Approche probabiliste, Approche par barrières », Institut National de 1 'Environnement Industriel et des Risques, mars 2004.

[20] Fiches méthodes, Groupe de travail Management Méthodes Outils Standard (M2OS), avril 2006.

[21] S. Bloch-Mercier, C. Cocozza-Thivent, M. Roussignol, «Divers modèles stochastiques pour l'optimisation de la maintenance », Journal de la Société Française de Statistique, tome 141, n³, 2000.

[22] C. Meier-Hirmer, F. Sourget, M. Roussignol, « Estimation de la durée de vie des pièces caténaires", 6ème Congrès international pluridisciplinaire, Qualité et Sûreté de Fonctionnement, Qualita 2005, mars 2005.

[23] B. Castanier, C. Bérenguer et A. Grall, « A Sequential Condition-Based Repair/Replacement Policy with Non Periodic Inspections for a System subject to Continuous Wear », Applied Stochastic Models in Business and Industry, vol.19, $\mathrm{n}^{\circ} 4$, p. 327-347, 2003.

[24] M.A. Boyd, "What Markov Modeling can do for you: An Introduction », Annual Reability and Maintainability Symposium, Tutorial notes, 1994.

[25] J. Lonchampt, "Méthode matricielle de quantification des risques associés à la maintenance d'un composant par un modèle semimarkovien », 6ème Congrès international pluridisciplinaire, Qualité et Sûreté de Fonctionnement, Qualita 2005, mars 2005.

[26] P. Lezaud, «Etude des Réseaux de Petri Stochastiques », mémoire de DEA de Mathématiques Appliquées, Université Paul Sabatier, Toulouse III, juin 1995.

[27] R. Garnier, «Une méthode efficace d'accélération de la simulation des réseaux de Petri stochastiques », Thèse de doctorat, Université de Bordeaux 1, 1998. 
[28] R. David, H. Alla, « Petri Nets for Modeling Dynamic systems - A Survey », Automatica, Vol.40, No.2, pp.175-202, 1994.

[29] M. Ajmone, G. Balgo, G. Conte, S. Donatelli, G. Franceshinis, «Modelling with Generalized Stochastic Petri Nets », John Willey \& Sons Ltd., Series in Parallel Computing, Chichester, England, 1995.

[30] A. Aghasaryan, «Formalisme HMM pour les réseaux de Petri partiellement stochastiques: Application au diagnostic des pannes dans les systèmes répartis », Thèse de doctorat, Université de Rennes 1, 1998.

[31] M. Ajmone, G. Balgo, G. Conte, «A class of Generalized Stochastic Petri Nets for performance Analysis of Multiprocessor Systems », ACM Transactions on Computer Systems, Vol.2, No.2, pp.93-122, may 1984.

[32] Norme Internationale / International Standard: CEI/IEC 60300-3-14, Première Edition / First Edition, mars 2004.

[33] P. Vrignat, « Modélisation des dysfonctionnements d'un système dans le cadre d'activités de maintenance ", Rapport de stage Master 2 Recherche, 2007.

[34] Advanced Industrial Automation, Production zéro défaut dans l'industrie automobile, OMRON, BRL_AUTO_MS-FR02_0105.

[35] D. Saint-Voirin, «Contribution à la modélisation et à l'analyse des systèmes coopératifs : application à la e-maintenance » Thèse, LIFC, Université de Franche-Comté, 2006.

[36] L. Déchamp, A. Dutech, T. Montroig, X. Qian, D. Racoceanu, I. Rasovska, B. Brézillon, F.Charpillet, J-Y. Jaffray, N. Moine, B. Morello, S. Müller, G. Nguengang, N. Palluat, L.Pelissier, « On the Use of Artificial Intelligence for Prognosis and Diagnosis in the PROTEUS E-maintenance platform », In Proc. of Int. Conf. on Mechatronics and Robotics, (MECHROB'04), Aachen, Deutchland,2004.

[37] http://www.proteus.fr/

[38] http://www.industry.siemens.com/industrialservices/en/solution_service s/SIMATIC_Addons/fuzzy.htm

\section{BIOGRAPHIES}

Pascal Vrignat born 08/07/1966. He has been working since 1996 at the Electronics \& Electrical Engineering department of the Institute of Technology of Chateauroux, Orleans University. Activities are linked to the control of industrial processes. Today in thesis, he is working on the guidelines work for the emaintenance implementing methods using the Hidden Markov Model. PRISME Institute - Team MCDS

Manuel Avila born 16/07/1969. PhD in Automation \& Computer Science. Currently, he heads the Electronics \& Electrical Engineering department at the Institute of Technology of Chateauroux, Orleans University. His main research activities are in vision \& automation. PRISME Institute - TeamSEISME.

Florent Duculty born 23/12/1972. PhD in Automation \& Computer Science. During is thesis he worked at the LASMEA laboratory. He is working in the Electronics \& Electrical Engineering department of the Institute of Technology of Chateauroux, Orleans University. His main research activities are in vision \& automation. PRISME Institute - TeamSEISME.

Frédéric Kratz was born on Metz, France in 1962. He received the master's degree in engineering in 1988 from the Ecole Nationale Supérieure de Physique de Strasbourg, France, the Ph.D. degree in electrical engineering in 1991 from the University of Nancy, France and his Accreditation to supervise researches in electrical engineering in 1998 from the Institute National Polytechnique de Lorraine (INPL). He has been employed at the INPL from 1992 to 2000 as an assistant professor and from 2000 to 2005 at the University of Orleans, France as a professor. Since 2005, he is professor at the National High School of Bourges. His interests include process control, diagnosis. He is then head of the theme Modelisation, Control and Diagnosis of Systems of the Institute PRISME. 